\title{
A Comparative Pharmacokinetic Study to Evaluate the Bioequivalence and Safety of A Humanized Recombinant Monoclonal Antibody Targeting Human Epidermal Growth Factor Receptor 2 (HER2) with the Reference Herceptin in Healthy Chinese Subjects
}

\section{Fangfang Ding}

Central South University Xiangya School of Pharmaceutical Sciences

Jie Huang

Central South University Third Xiangya Hospital

\section{Zeying Feng}

Central South University Xiangya School of Pharmaceutical Sciences

Yun Kuang

Central South University Third Xiangya Hospital

Shuang Yang

Central South University Third Xiangya Hospital

\section{Yuxia Xiang}

Central South University Third Xiangya Hospital

\section{Chan Zou}

Central South University Third Xiangya Hospital

Guoping YANG ( $\nabla$ ygp9880@126.com)

Central South University Third Xiangya Hospital https://orcid.org/0000-0001-5930-586X

\section{Research Article}

Keywords: Bioequivalence, Herceptin, Pharmacokinetic, Safety

Posted Date: January 11th, 2022

DOI: https://doi.org/10.21203/rs.3.rs-1124196/v1

License: (c) (1) This work is licensed under a Creative Commons Attribution 4.0 International License. Read Full License 


\section{Abstract}

\section{Purpose:}

This study aimed to evaluate the safety, tolerability, pharmacokinetics and bioequivalence of a test humanized recombinant monoclonal antibody targeting Human Epidermal Growth Factor receptor 2 (HER-2) with the reference Herceptin ${ }^{\circledR}$.

\section{Materials and methods:}

The trial consists of two parts (part I and part II). Part I was an open-label, sequential-cohort doseescalation study, QLHER2 (test) was intravenous infusion at single doses escalating from 0.2 to $6 \mathrm{mg} / \mathrm{kg}$ $(0.2,1,2,4$ and $6 \mathrm{mg} / \mathrm{kg}$ ) and Herceptin(reference) $4 \mathrm{mg} / \mathrm{kg}$ in 16 healthy subjects, to evaluated the safety, tolerability and pharmacokinetics of QLHER2. Part II was a randomized, double-blind, parallel-group study to evaluate the bioequivalence of QLHER2 and Herceptin in 60 subjects.

\section{Results:}

Following a 1.5-h intravenous infusion of single ascending doses of QLHER2 (1, 2, 4, or $6 \mathrm{mg} / \mathrm{kg})$ In part I, $\mathrm{C}_{\max }$ and $\mathrm{T}_{\max }$ were 19.43-120.01 $\mathrm{gg} / \mathrm{mL}$ and 68.91-157.87 $\mathrm{h}$, respectively. $A U \mathrm{C}_{0-\mathrm{t}}$ and $\mathrm{CL}$ were 1.91$34.21 \mathrm{~h} \mu \mathrm{g} / \mathrm{mL}$ and $0.54-0.12 \mathrm{ml} / \mathrm{h} / \mathrm{kg}$, indicating decreased clearance at higher doses, with a greater than proportional increase in the $\mathrm{AUC}_{0-\mathrm{t}}$, and the $\mathrm{t}_{1 / 2}$ was 68.91-157.87 h. In part II, Plasma concentrations appeared to be comparable between QLHER2 and Herceptin over the 70-day sampling period and the QLHER2/Herceptin ratio of the $\mathrm{C}_{\max }$ and $\mathrm{AUC}_{0-\mathrm{t}}$ was $105.90 \%$ (90\% Cl: 95.69-117.26) and 95.79\% (90\% Cl: 87.74-106.40\%), respectively.

\section{Conclusion:}

The $90 \%$ Cls of the $\mathrm{C}_{\max }$ and $\mathrm{AUC}_{0-\mathrm{t}}$ for QLHER2/Herceptin ratio were within the range of $80.0-125.00 \%$ indicated that QLHER2 was bioequivalent to Herceptin. The results supported for further evaluation of QLHER2.

Trial registration number: ChiCTR2000041577 and ChiCTR2100041802

Date of registration: December 30,2020 and January 5, 2021

\section{Introduction}

Human epidermal growth factor receptor 2 (EGFR2), also known as HER2/neu or ErbB-2, is a receptor tyrosine kinase that regulates cell growth and apoptosis by activating downstream cell signaling pathways, and also closely related to cell adhesion, migration, differentiation and other cellular response functions(Arboleda et al., 2003). Nowadays the key role of HER2 in the development and progression of several aggressive types of cancer is well established, notably breast cancer(Farmahini Farahani et al., 
2020; Li et al., 2018). Approximately 20 - 30\% of breast cancer patients with high expression of HER2 correlated with a more aggressive disease and worse prognosis(Hudis, 2007).

Trastuzumab(Herceptin $®$ ), a humanized recombinant monoclonal anti-HER2 antibody, exerts potent antitumor effects by binding to the extracellular juxtamembrane domain of HER2 and inhibits the proliferation and survival of HER2-dependent tumors(Hudis, 2007). Herceptin was developed by Genentech Lnc. and received global approval on February 22, 2013 for the treatment of patients with HER2-positive metastatic breast cancer(Ballantyne \& Dhillon, 2013). Shortly thereafter, Herceptin-based therapies become the mainstay in the treatment of HER2-overexpressing metastatic breast, gastric and gastroesophageal junction adenocarcinoma(Eiermann, 2001; Slamon et al., 2011; Wang \& Xu, 2019). Although the safety and efficacy of Herceptin has been well recognized, the relatively high costs limit its use in most developing countries including China. Therefore, development of high-quality and affordable biosimilars of Herceptin are encouraging and will benefit patients in China.

Recently, QLHER2, a new biosimilar medicine of trastuzumab has been developed by Qilu Pharmaceutical Co. Ltd. in China. Although this product was generated using Chinese hamster ovary cells, we noticed that both the primary and secondary structures of QLHER2 are similar to Herceptin, our preclinical studies have demonstrated that the physicochemical properties of QLHER2 were comparable to Herceptin (unpublished data). However, the safety and efficacy of these biosimilars still required to be rigorously and thoroughly evaluated because of the structural complexity of biomacromolecules. Therefore, the primary objective of this study was to evaluate the bioequivalence of pharmacokinetics (PK) between QLHER2 and Herceptin, the secondary objective was to evaluate the safety and tolerability of QLHER2 in healthy Chinese adults.

\section{Materials And Methods}

\section{Ethics statement}

The Phase I study was conducted in the Third Xiangya Hospital of Central South University and in accordance with the Declaration of Helsinki and the Good Clinical Practice of the International Conference on Harmonization (ICH-GCP). The study protocol and informed consent documents were approved by the Ethics Committee of the Third Xiangya Hospital of Central South University, Changsha, Hunan, P. R. China (approval No.13072). Written informed consents were provided by all subjects prior to participating in any study-related activities in the study (Registered on China, No. ChiCTR2000041577 and ChiCTR2100041802).

\section{Study drugs}

The test recombinant humanized monoclonal antibody against HER2 for injection was manufactured by Qilu Pharmaceutical Co. Ltd (specification:150mg/vail; batch number:20130401), the reference product Herceptin was manufactured by Roche Pharma (Schweiz) Ltd. (specification:20mL:440mg; batch number:SH0027). 


\section{Volunteers}

Eligible subjects were healthy males aged 18 to 45 years, weight $\geq 50 \mathrm{~kg}$ with a body mass index between 19 and $25 \mathrm{~kg} / \mathrm{m}^{2}$ and a baseline left ventricle ejection fraction (LVEF) $₫ 60 \%$. Physical examination, blood pressure, electrocardiography, echocardiography and routine laboratory tests were performed for all subjects at screening period. Exclusion criteria included hemoptysis, thrombotic or hemorrhagic event or cerebral vascular accident, transient ischemic attack, or subarachnoid hemorrhage within 6 months before administration of study drug; undergone surgery within 4 weeks before the trial; allergic or known to be allergic to this product or any excipients; with a history of clinical serious illness or any other diseases or physiological conditions that can interfere with the results of the study.

\section{Study design}

This phase I study consists of two parts. Part I was a first-in-human dose-escalating study, which adopted an open-label, sequential-cohort design to define the maximum dose of QLHER2 (range from 0.2 to 6 $\mathrm{mg} / \mathrm{kg}$ ) in 16 healthy volunteers. Part II was a randomized, double-blind, parallel study to evaluate the bioequivalence of QLHER2 and Herceptin in 60 healthy volunteers. Volunteers received either drug at a single dose on day 1 and follow up to day 70 . The flow chart of the two-part phase I study is shown in Fig. 1.

In part I, QLHER2 0.2 to $6 \mathrm{mg} / \mathrm{kg}(0.2,1,2,4$ and $6 \mathrm{mg} / \mathrm{kg})$ and Herceptin $4 \mathrm{mg} / \mathrm{kg}$ was intravenous infusion at a single dose escalated in cohorts of one or three subjects. Drugs were diluted with $250 \mathrm{~mL}$ of $0.9 \% \mathrm{NaCl}$ and infused intravenously for $90 \mathrm{~min}$. One subject infused QLHER2 $0.2 \mathrm{mg} / \mathrm{kg}$ without collecting any blood samples but only for observation, to evaluate the overall safety of QLHER2 in healthy adults during the infusion period and one week thereafter. If no severe allergic reactions or other conditions observed, we started the next sequential dosing in 3 volunteers from 1 to $6 \mathrm{mg} / \mathrm{kg}$. Among the same dosing cohort, one out of every three volunteers administrated the drug first, with a 1-3 days' observation period proved its safety, then the other two subjects received the same dose and observed for another week. The only exception is that in the $4 \mathrm{mg} / \mathrm{kg}$ dose cohort, 6 volunteers were randomized equally to receive QLHER2 $4 \mathrm{mg} / \mathrm{kg}$ or Herceptin $4 \mathrm{mg} / \mathrm{kg}$. Blood samples were collected at determined time points. If any serious allergic reactions or other conditions observed in any of the dose groups, the dose-escalating study will be terminated.

In part II, 60 subjects were enrolled and randomized in a 1:1 ratio to either receiving 4-mg/kg QLHER2 or $4-\mathrm{mg} / \mathrm{kg}$ Herceptin. All volunteers underwent intensive monitoring for one week after drug administration. Blood samples were collected at determined time points.

\section{Safety evaluation}

Safety was assessed based on adverse event (AE) monitoring and follow-up interviews. All subjects received physical examinations, vital signs (blood pressure, heart rate, respiratory rate and body temperature), 12-lead electrocardiography, echocardiography, laboratory tests (routine blood, routine urine, liver and kidney function, blood glucose, blood lipid, plasma electrolytes, myocardial enzymes, 
coagulation function, four pre-transfusion tests) during the study period and at the 70-day follow-up visit period. The clinical significance of abnormal laboratory test values was determined by the physicians. Treatment-related AEs were graded based on the National Cancer Institute Common Terminology Criteria for Adverse Events (version 4.0). Subjects with AEs were monitored until the conditions were resolved or stabilized(Yang et al., 2020).

\section{Sample collection and analysis}

Venous blood samples $(5 \mathrm{~mL})$ were collected prior to dosing, at $0.5,1,1.5 \mathrm{~h}$ during infusion and $0.5,1,1.5$, $2,3,4,6,8,12 \mathrm{~h}$ on day 1 and day $2,3,4,5,6,7,14 \pm 1,21 \pm 1,28 \pm 1,35 \pm 1,42 \pm 1,49 \pm 1,56 \pm 1,63 \pm 1$, 70 after infusion. Blood samples were centrifuged at $3000 \mathrm{rpm} / \mathrm{min}$ for $15 \mathrm{~min}$ at $4^{\circ} \mathrm{C}$. Plasma was separated and kept at $-70^{\circ} \mathrm{C}$ until further bioanalysis. Serum QLHER2 and Herceptin were determined using enzyme-linked chemiluminescent assays (ELISA). The lower limit of quantitation (LLOQ) was 3.125 $\mathrm{ng} / \mathrm{mL}$ (calibration range, 3125 to $200 \mathrm{ng} / \mathrm{mL}$ ). Raw data were input and processed by SoftMax Pro Software (version 1.6.3). The range of precision deviation between batches of precision range (CV) was below $15 \%$. These values were within the criteria shown in the guidelines for the ligand-binding assay (Committee, 2015), suggesting that plasma concentrations of QLHER2 and Herceptin measured were reliable.

\section{Data Analysis}

Major pharmacokinetic parameters include $\mathrm{C}_{\max }$ (peak concentration), $\mathrm{AUC}_{0-\infty}$ (area under the indacaterol concentration in plasma vs time curve from dosing to infinity), $\mathrm{AUC}_{0-\mathrm{t}}$ (area under the indacaterol concentration in plasma vs time curve from dosing to any of time-point), $T_{\max }$ (time to reach peak concentration) and $t_{1 / 2}$ (half elimination time) were calculated using the noncompartmental model (NCA module), Phoenix WinNonlin 6.2 (Pharsight Corporation, Mountain View, CA, USA). Linear up-log down method was employed in the estimation of AUC. $C_{\text {max }}, T_{\text {max }}, A_{U C} C_{0-t}$ were compared to assess the bioequivalence of QLHER2 and Herceptin. The $90 \%$ confidence intervals (Cls) were estimated from the ANOVA model. $90 \%$ Cls of $C_{\text {max }}, A \mathrm{UC}_{0-t}, \mathrm{AUC}_{0-\infty}$ for the QLHER2/Herceptin ratio between $80.00-125.00 \%$ considered to be equivalence(Zou et al., 2020).

\section{Results}

\section{Demographic characteristics}

A total of 76 healthy volunteers were enrolled in the study, the baseline demographic information are shown in Table S1. There were no significant differences in age, height, weight, and body mass index (BMI) among all groups. Three subjects in part II were not included for further safety or bioequivalence evaluation, because one of them lost follow up in the third week after drug administration and the other two withdrew from the study on their own initiative after 5- or 9-week follow-up.

\section{Pharmacokinetic Profiles}


Pharmacokinetic parameters and mean plasma concentration-time profiles of QLHER2 following a 1.5-h intravenous infusion of single ascending doses of QLHER2 (1, 2, 4, or $6 \mathrm{mg} / \mathrm{kg}$ ) was presented in Table S2 and Figure 2. QLHER2 $\mathrm{C}_{\max }$ and $\mathrm{T}_{\max }$ were 19.43-120.01 $\mu \mathrm{g} / \mathrm{mL}$ and 68.91-157.87 h, respectively, indicating that the plasma concentrations of QLHER2 are linearly increased with dose proportional increases over the dose range of 1-6 mg/kg. QLHER2 $\mathrm{AUC}_{0-\mathrm{t}}$ and CL were 1.91-34.21 $\mathrm{h} * \mu \mathrm{g} / \mathrm{mL}$ and 0.54$0.12 \mathrm{~mL} / \mathrm{h} / \mathrm{kg}$, indicating decreased clearance at higher doses, with a greater than proportional increase in the $A_{U C} C_{0-t}$, and the $t_{1 / 2}$ was 68.91-157.87 h. All above exhibited a non-linear pharmacokinetic profile of QLHER2. Moreover, there was no significant difference in pharmacokinetic profiles between 4-mg/kg QLHER2 and 4-mg/kg Herceptin.

\section{Bioequivalence Analysis}

The main pharmacokinetic parameters following a 1.5-h intravenous infusion of 4-mg/kg QLHER2 and Herceptin were summarized in Table 3. The $C_{\max }$ and $A_{U C-t}$ were $95.38 \pm 22.86 \mu \mathrm{g} / \mathrm{mL}$ and $19.80 \pm 40.37$ $\mathrm{mg} \cdot \mathrm{h} / \mathrm{mL}$ for QLHER2 and $90.06 \pm 21.91 \mu \mathrm{g} / \mathrm{mL}$ and 20.67 $\pm 50.60 \mathrm{mg} \bullet \mathrm{h} / \mathrm{mL}$ for Herceptin, respectively. The concentration-time profiles were showed in Figure 3. Plasma concentrations appeared to be comparable between QLHER2 and Herceptin over the 70-day sampling period. For bioequivalence analysis, the QLHER2/Herceptin ratio of the $C_{\max }$ and $\mathrm{AUC}_{0-\mathrm{t}}$ was $105.90 \%$ (90\% $\mathrm{Cl}$ : 95.69-117.26) and 95.79\% (90\% Cl: 87.74-106.40\%), respectively, which was within the acceptance range of $80.00-125.00 \%$ (Table S3).

\section{Safety}

A total of 173 drug-related adverse events (AEs) were reported in the study, including 93 QLHER2-induced AEs and 80 Herceptin-induced AEs. The most common AEs were direct bilirubin elevation(32/173), upper respiratory tract infection (19/173) and fever(14/173). The severity of most AEs were classified as mild, except 28 AEs were moderate, no serious AEs were observed and no volunteers withdrew from the study because of AEs(Table S4).

\section{Discussion}

QLHER2 is a new biosimilar medicine of trastuzumab developed in China recently. This two-part phase I study was performed to investigate the safety, tolerability, pharmacokinetics and bioequivalece of QLHER2 compare to Herceptin in healthy volunteers. Following a 1.5-h intravenous infusion of single ascending doses of QLHER2 (1, 2, 4, or $6 \mathrm{mg} / \mathrm{kg})$ in part I was well tolerated and exhibited a non-linear pharmacokinetic profile of QLHER2 in healthy subjects. Part II adopted a randomized, double-blind, parallel study to evaluate the bioequivalence of QLHER2 and Herceptin following a 1.5-h intravenous infusion of single dose of $4 \mathrm{mg} / \mathrm{kg}$ in healthy volunteers. The $90 \% \mathrm{Cls}_{\text {of }}$ the $\mathrm{C}_{\text {max }}$ and $\mathrm{AUC}_{0-\mathrm{t}}$ for QLHER2/Herceptin ratio were within the range of 80.0-125.00\% (95.69-117.26\% and 87.74-106.40\%, respectively), we concluded that QLHER2 was bioequivalent to Herceptin. 
Since this is the first-in-human study for QLHER2, we first explored the optimal dose for the bioequivalence study. Literatures reported that the targeted steady-state trough concentration for Herceptin $4 \mathrm{mg} / \mathrm{kg}$ in clinical management of HER2-overexpression breast cancer is $20000 \mathrm{ng} / \mathrm{mL}$ (Loibl \& Gianni, 2017).Generally, concentration in the range of $35200-44900 \mathrm{ng} / \mathrm{mL}$ was accepted, which is consistent with the results presented in our study $(41803.10 \mathrm{ng} / \mathrm{mL}$ on day 7 at a single dose of 4 $\mathrm{mg} / \mathrm{kg}$ ). Moreover, $X X$ et al. reported that the $C_{\max }$ was $43413 \mathrm{ng} / \mathrm{mL}$ and the $t_{1 / 2}$ was 3.1 days after a single intravenous administration of $2 \mathrm{mg} / \mathrm{kg}$ in Japanese breast cancer patients, so it could be inferred that the blood concentration on day 7 was about $10853 \mathrm{ng} / \mathrm{mL}$ (Tokuda et al., 1999), which is comparative to that of our results (12300-13500 $\mathrm{ng} / \mathrm{mL}$ on day 7 at a single dose of $2 \mathrm{mg} / \mathrm{kg}$ ). Since the plasma concentration was $30968-40093 \mathrm{ng} / \mathrm{mL}$ at day 21 after dose $6 \mathrm{mg} / \mathrm{kg}$, which was higher than the target steady state trough concentration(Baselga et al., 2005). Therefore, QLHER2 dose of $4 \mathrm{mg} / \mathrm{kg}$ was chosen for the following bioequivalence study.

In terms of safety, Morita $J$ et. al reported that the most common AE for recombinant QLHER2 human monoclonal antibody injection was fever, followed by elevation of direct bilirubin, with a incidence of $46.7 \%$ and $40.0 \%$, respectively(Morita et al., 2016). Sandra M Swain et. al found that elevation of direct bilirubin and upper respiratory tract infection were most common AEs after trastuzumab administration in their study, with an incidence of 53.3\% and 33.3\%, respectively(Swain et al., 2014). All reported AEs were mild or moderate, and no serious adverse reactions(Yin et al., 2014; Zhang et al., 2021; Zhou et al., 2020). QLHER2 and Herceptin were well tolerated in our study, and most types of drug-related AEs were reported in the literatures.

One limitation in this study is that immunogenicity assessment was not be considered under certain experimental conditions. Since both drugs were well tolerated and we have noticed that no immunologically related adverse events were reported, we inferred that it shouldn't have an impact on our results. Especially, several ongoing trials are expanded the clinical indications of trastuzumab, for examples, Yelena et. al added trastuzumab to first-line therapy for esophageal cancer, gastric cancer, and esophagogastric junction cancer (Janjigian et al., 2020), Amanda et. al applied carboplatin-paclitaxeltrastuzumab on advanced or recurrent uterine serous carcinoma who overexpress HER2/neu(Fader et al., 2018) and Martine et al proved that trastuzumab treatment after adjuvant therapy can significantly improve the survival rate of HER2-positive breast cancer(von Minckwitz et al., 2019). Development of biosimilar medicines of trastuzumab will benefit a large number of cancer patients in the future.

\section{Conclusion}

We investigated the safety, tolerability, pharmacokinetics and bioequivalence of QLHER2, a biosimilar trastuzumab, to reference trastuzumab in healthy Chinese subjects. The dose-escalation period, QLHER2 was well tolerated in the dose range of $0.2-6 \mathrm{mg} / \mathrm{kg}$. In the bioequivalence part, we found that both drugs were bioequivalent, the safety and immunogenicity profiles were also similar. These similarity results provide critical evidence for future clinical trials of QLHER2. 


\section{Declarations}

\section{Ethics approval and consent to participate}

Informed consent was obtained from all individual participants included in the study

Consent to publish

The authors affirm that human research participants provided informed consent for publication of the images in Table S1.

\section{Availability of data and materials (not appropriate)}

\section{Competing Interests}

The authors declare that the research was conducted in the absence of any commercial or financial relationships that could be construed as a potential conflict of interest.

\section{Funding}

This work was supported by National Natural Science Foundation of China (No. 81803639); Hunan

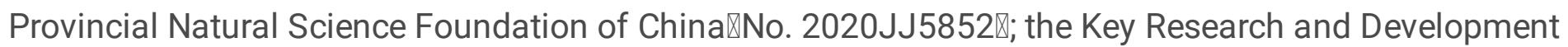
Project of Hunan Province $₫ 2020$ SK2010区.

\section{Author contributions}

All authors contributed to drafting this manuscript by providing critical revisions and important intellectual content, and all approved the final version for submission.FFD and JH were involved in the design and analyze data of the study. YK,SY, ZYF,CZ were responsible for the project implementation, CZ and YXX were responsible for the analysis of blood samples, GPY was the principal investigator.

\section{Acknowledgements(not appropriate)}

\section{Ethics approval}

This study was performed in line with the principles of the Declaration of Helsinki. Approval was granted by the Ethics Committee of Third Xiangya Hospital, Central South University (No2013L1520)

\section{Disclosure of potential conflicts of interest(not appropriate)}

Research involving Human Participants and/or Animals(not appropriate)

Informed consent

Informed consent was obtained from all individual participants included in the study 


\section{References}

1. Arboleda, M. J., Lyons, J. F., Kabbinavar, F. F., Bray, M. R., Snow, B. E., Ayala, R., Danino, M., Karlan, B. Y., \& Slamon, D. J. (2003). Overexpression of AKT2/protein kinase Bbeta leads to up-regulation of beta 1 integrins, increased invasion, and metastasis of human breast and ovarian cancer cells. Cancer Res, 63(1), 196-206.

2. Ballantyne, A., \& Dhillon, S. (2013). Trastuzumab emtansine: first global approval. Drugs, 73(7), 755765. https://doi.org/10.1007/s40265-013-0050-2

3. Baselga, J., Carbonell, X., Castañeda-Soto, N. J., Clemens, M., Green, M., Harvey, V., Morales, S., Barton, C., \& Ghahramani, P. (2005). Phase II study of efficacy, safety, and pharmacokinetics of trastuzumab monotherapy administered on a 3-weekly schedule. J Clin Oncol, 23(10), 2162-2171. https://doi.org/10.1200/jco.2005.01.014

4. Committee, N. P. (2015). Pharmacopoeia of the People's Republic of China part $\rrbracket$.

5. Eiermann, W. (2001). Trastuzumab combined with chemotherapy for the treatment of HER2-positive metastatic breast cancer: pivotal trial data. Ann Oncol, 12 Supp/ 1, S57-62.

6. Fader, A. N., Roque, D. M., Siegel, E., Buza, N., Hui, P., Abdelghany, O., Chambers, S. K., Secord, A. A., Havrilesky, L., O'Malley, D. M., Backes, F., Nevadunsky, N., Edraki, B., Pikaart, D., Lowery, W., ElSahwi, K. S., Celano, P., Bellone, S., Azodi, M., Litkouhi, B., Ratner, E., Silasi, D. A., Schwartz, P. E., \& Santin, A. D. (2018). Randomized Phase II Trial of Carboplatin-Paclitaxel Versus Carboplatin-PaclitaxelTrastuzumab in Uterine Serous Carcinomas That Overexpress Human Epidermal Growth Factor Receptor 2/neu. J Clin Oncol, 36(20), 2044-2051. https://doi.org/10.1200/jco.2017.76.5966

7. Farmahini Farahani, M., Maghzi, P., Jafari Aryan, N., Payandemehr, B., Soni, M., \& Azhdarzadeh, M. (2020). A randomized, double-blind, parallel pharmacokinetic study comparing the trastuzumab biosimilar candidate, AryoTrust ${ }^{\circledR}$, and reference trastuzumab in healthy subjects. Expert Opin Investig Drugs, 29(12), 1443-1450. https://doi.org/10.1080/13543784.2020.1831470

8. Hudis, C. A. (2007). Trastuzumab--mechanism of action and use in clinical practice. N Engl J Med, 357(1), 39-51. https://doi.org/10.1056/NEJMra043186

9. Janjigian, Y. Y., Maron, S. B., Chatila, W. K., Millang, B., Chavan, S. S., Alterman, C., Chou, J. F., Segal, M. F., Simmons, M. Z., Momtaz, P., Shcherba, M., Ku, G. Y., Zervoudakis, A., Won, E. S., Kelsen, D. P., Ilson, D. H., Nagy, R. J., Lanman, R. B., Ptashkin, R. N., Donoghue, M. T. A., Capanu, M., Taylor, B. S., Solit, D. B., Schultz, N., \& Hechtman, J. F. (2020). First-line pembrolizumab and trastuzumab in HER2positive oesophageal, gastric, or gastro-oesophageal junction cancer: an open-label, single-arm, phase 2 trial. Lancet Oncol, 21(6), 821-831. https://doi.org/10.1016/s1470-2045(20)30169-8

10. Li, B. T., Shen, R., Buonocore, D., Olah, Z. T., Ni, A., Ginsberg, M. S., Ulaner, G. A., Offin, M., Feldman, D., Hembrough, T., Cecchi, F., Schwartz, S., Pavlakis, N., Clarke, S., Won, H. H., Brzostowski, E. B., Riely, G. J., Solit, D. B., Hyman, D. M., Drilon, A., Rudin, C. M., Berger, M. F., Baselga, J., Scaltriti, M., Arcila, M. E., \& Kris, M. G. (2018). Ado-Trastuzumab Emtansine for Patients With HER2-Mutant Lung Cancers: Results From a Phase II Basket Trial. J Clin Oncol, 36(24), 2532-2537. https://doi.org/10.1200/jco.2018.77.9777 
11. Loibl, S., \& Gianni, L. (2017). HER2-positive breast cancer. Lancet, 389(10087), 2415-2429. https://doi.org/10.1016/s0140-6736(16)32417-5

12. Morita, J., Tanaka, M., Nomoto, M., Matsuki, S., Tsuru, T., Matsuguma, K., \& Shiramoto, M. (2016). Pharmacokinetic Bioequivalence, Safety, and Immunogenicity of DMB-3111, a Trastuzumab Biosimilar, and Trastuzumab in Healthy Japanese Adult Males: Results of a Randomized Trial. BioDrugs, 30(1), 17-25. https://doi.org/10.1007/s40259-015-0153-2

13. Slamon, D., Eiermann, W., Robert, N., Pienkowski, T., Martin, M., Press, M., Mackey, J., Glaspy, J., Chan, A., Pawlicki, M., Pinter, T., Valero, V., Liu, M. C., Sauter, G., von Minckwitz, G., Visco, F., Bee, V., Buyse, M., Bendahmane, B., Tabah-Fisch, I., Lindsay, M. A., Riva, A., \& Crown, J. (2011). Adjuvant trastuzumab in HER2-positive breast cancer. N Engl J Med, 365(14), 1273-1283. https://doi.org/10.1056/NEJMoa0910383

14. Swain, S. M., Im, Y. H., Im, S. A., Chan, V., Miles, D., Knott, A., Clark, E., Ross, G., \& Baselga, J. (2014). Safety profile of Pertuzumab with Trastuzumab and Docetaxel in patients from Asia with human epidermal growth factor receptor 2-positive metastatic breast cancer: results from the phase III trial CLEOPATRA. Oncologist, 19(7), 693-701. https://doi.org/10.1634/theoncologist.2014-0033

15. Tokuda, Y., Watanabe, T., Omuro, Y., Ando, M., Katsumata, N., Okumura, A., Ohta, M., Fujii, H., Sasaki, Y., Niwa, T., \& Tajima, T. (1999). Dose escalation and pharmacokinetic study of a humanized antiHER2 monoclonal antibody in patients with HER2/neu-overexpressing metastatic breast cancer. $\mathrm{Br} J$ Cancer, 81(8), 1419-1425. https://doi.org/10.1038/sj.bjc.6690343

16. von Minckwitz, G., Huang, C. S., Mano, M. S., Loibl, S., Mamounas, E. P., Untch, M., Wolmark, N., Rastogi, P., Schneeweiss, A., Redondo, A., Fischer, H. H., Jacot, W., Conlin, A. K., Arce-Salinas, C., Wapnir, I. L., Jackisch, C., DiGiovanna, M. P., Fasching, P. A., Crown, J. P., Wülfing, P., Shao, Z., Rota Caremoli, E., Wu, H., Lam, L. H., Tesarowski, D., Smitt, M., Douthwaite, H., Singel, S. M., \& Geyer, C. E., Jr. (2019). Trastuzumab Emtansine for Residual Invasive HER2-Positive Breast Cancer. N Eng/ J Med, 380(7), 617-628. https://doi.org/10.1056/NEJMoa1814017

17. Wang, J., \& Xu, B. (2019). Targeted therapeutic options and future perspectives for HER2-positive breast cancer. Signal Transduct Target Ther, 4, 34. https://doi.org/10.1038/s41392-019-0069-2

18. Yang, G., Huang, R., Yang, S., Zhang, X., Yang, X., Chen, H., Huang, Z., Guo, C., Pei, Q., Tai, Y., Shen, Y., Huang, J., \& Zou, C. (2020). Effect of postdose fasting duration on hetrombopag olamine pharmacokinetics and pharmacodynamics in healthy volunteers. Br J Clin Pharmacol, 86(8), 15281536. https://doi.org/10.1111/bcp.14259

19. Yin, D., Barker, K. B., Li, R., Meng, X., Reich, S. D., Ricart, A. D., Rudin, D., Taylor, C. T., Zacharchuk, C. M., \& Hansson, A. G. (2014). A randomized phase 1 pharmacokinetic trial comparing the potential biosimilar PF-05280014 with trastuzumab in healthy volunteers (REFLECTIONS B327-01). Br J Clin Pharmacol, 78(6), 1281-1290. https://doi.org/10.1111/bcp.12464

20. Zhang, H., Liu, T., Wu, M., Wei, H., Li, C., Li, X., Liu, J., Chen, H., Ding, Y., \& Liu, L. (2021). Safety and pharmacokinetics of a new biosimilar trastuzumab (HL02): a Phase I bioequivalence study in healthy Chinese men. Expert Opin Biol Ther, 1-8. https://doi.org/10.1080/14712598.2021.1894121 
21. Zhou, H., Cao, S., Zhu, X., Xie, J., Fan, L., Ge, Q., Wang, Y., Zhu, J., Liu, Y., Shao, Z., Shan, R., Liu, B., Wang, H., \& Ding, L. (2020). A randomized Phase I pharmacokinetic trial comparing the potential biosimilar trastuzumab (SIBP-01) with the reference product (Herceptin $\left.{ }^{\circledR}\right)$ in healthy Chinese male volunteers. Expert Opin Drug Metab Toxicol, 16(10), 997-1003.

https://doi.org/10.1080/17425255.2020.1807935

22. Zou, C., Yang, Q., Yang, S., Zhang, X., Yang, X., Huang, Z., Pei, Q., Huang, J., \& Yang, G. (2020).

Bioequivalence studies of inhaled indacaterol maleate in healthy Chinese volunteers under gastrointestinal non-blocking or blocking with concomitant charcoal administration. Pulm

\section{Figures}

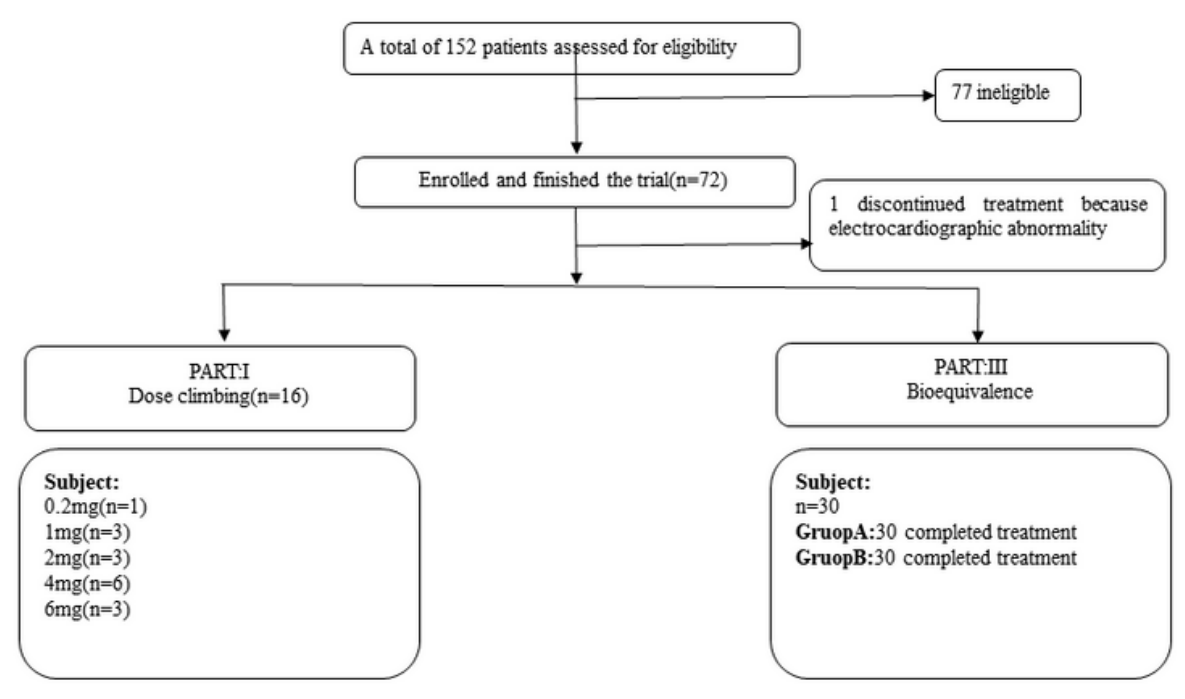

Figure 1

Flow chart of the two-part phase I study.

\section{Figure 2}

Mean plasma concentration-time curves of QLHER2 following a 1.5-h intravenous infusion of single ascending doses of QLHER2 (1, 2, 4, or $6 \mathrm{mg} / \mathrm{kg})$. 
Figure 3

Mean ( \pm SD) serum concentration-time curves of QLHER2 (Test) and Herceptin (Reference) following a $1.5-\mathrm{h}$ intravenous infusion of single dose of $4 \mathrm{mg} / \mathrm{kg}$ in healthy volunteers.

\section{Supplementary Files}

This is a list of supplementary files associated with this preprint. Click to download.

- SupplementaryMaterial.docx 